\title{
Arbuscular Mycorrhizal Fungi Enhance Plant Diversity, Density and Productivity of Spring Ephemeral Community in Desert Ecosystem
}

\author{
Zhaoyong SHI ${ }^{1,2 *}$, Yongming $\mathrm{WANG}^{1}$, Shouxia XU ${ }^{1}$, Zhijian $\mathrm{LAN}^{1}$, \\ Bede S. MICKAN ${ }^{3}$, Xiaolong ZHANG ${ }^{1}$, Fayuan WANG ${ }^{1,4}$
}

\author{
${ }^{1}$ Henan University of Science and Technology, College of Agriculture, Luoyang 471003, China; shizy1116@126.com ("corresponding author); \\ 1030079720@qq.com; xushoux@126.com;59618709@qq.com;1406703506@qq.com \\ ${ }^{2}$ Chinese Academy of Sciences, Key Laboratory of Mountain Surface Processes and Ecological Regulation, Chengdu 610041, China \\ ${ }^{3}$ The University of Western Australia, The UWA Institute of Agriculture, LB 500 WA 6001, Australia; bedemickan@gmail.com \\ ${ }^{4}$ Qingdao University of Science \& Technology, College of Environment and Safety Engineering, Qingdao, \\ 266042, Shandong Province, China;wfy1975@163.com
}

\begin{abstract}
Arbuscular mycorrhizal (AM) fungi form intimate associations with the roots of about $85 \%$ of all terrestrial plants, and can greatly increase a plant's uptake of soil nutrients and have been shown to influence plant diversity in several ecosystems. A lot of studies have reported the effect of arbuscular mycorrhizas on plant density, species diversity, richness and productivity in desert herbland in Gurbantonggut desert, China. Here, we conduct a mycorrhizal functional study by suppressing AM fungi by applying the fungicide benomyl as a soil drench in soil cores and field in-situ experiment. The mycorrhiza-responsiveness of the dominant species Erodium oxyrrhynchum is assessed in intact soil cores containing the indigenous AM fungi. The soil-cores experiment displayed E. oxyrrhynchum to have a significant positive shoot and root growth response, and this is in response to the abundance of the indigenous AM fungal colonisation. The field experiment indicates the total aboveground dry biomass is negatively influenced by the suppression of AM fungi, though, no significant effect produced in the dominant and common plant species. The fungal suppression also affected density, species diversity and richness. The density of non-mycorrhizal plant Alyssum linifolium increases significantly in the treatment of suppressed AM fungi. The spore density decreases significantly in benomyl-treated plots. Our results showed that AM fungi were very important in desert ecosystem for the maintaining of plant biodiversity, richness and productivity.
\end{abstract}

Keywords: colonization rate, fungicide, growth, nutrients, spore density, symbiosis

\section{Introduction}

Arbuscular mycorrhizal (AM) fungi can form intimate associations with the roots of about $85 \%$ of all terrestrial plants, and can greatly increase a plant's uptake of soil nutrients, especially phosphorus (Smith and Read, 2008). Heijden $e t$ al. (1998) shows that belowground diversity of arbuscular mycorrhizal fungi (AMF) is a major factor contributing to the maintenance of plant biodiversity and to ecosystem functioning. Recently, researchers have focused on the influence of arbuscular mycorrhiza on plant diversity and productivity in varying ecosystem (Heijden et al., 1998; Klironomos et al., 2000; O'Connor et al., 2002; Dhillion and Gardsjord, 2004; Horn et al., 2017).

Several studies have found that ecosystem processes such as primary productivity are linked to species diversity (Tilman $e t$ al., 1996, 1997; Klironomos et al., 2000; Jing et al., 2015; Fessel et al., 2016). While increasing species richness has been shown to increase primary productivity, species identity and functional group richness are also important factors controlling productivity (Tilman et al., 1997; Wilsey and Potvin, 2000). Results from experiments on the relationship between plant species richness and productivity have, however, been confounded by the 'hidden treatment' effects discussed by Givnish (1994) and Huston (1997). Some resolution to the question of whether increased productivity is a function of species identity or diversity has been offered by Klironomos et al. (2000) and Wilsey and Potvin (2000).

Lin et al. (2015) indicates that the magnitude and direction of AMF effects on plant competitive ability based on the results of 304 studies. Klironomos et al. (2000) indicates that AM symbionts must be considered in investigations of plant biodiversity and ecosystem function. Researches shows that the presence of mycorrhizas can influence plant diversity (Heijden 
302

et al., 1998; Klironomos et al., 2000; O'Connor et al., 2002; Dhillion and Gardsjord, 2004), species richness (Gange et al., 1990) and ecosystem function (Jing et al., 2015); however, this may depend on the identity and mycorrhizal responsiveness of the dominant plant species (Bergelson and Crawley, 1988). Further, on the basis of studies carried out in grasslands, it has been proposed that these results may not be in conflict but rather depend on mycorrhizal dependence of dominant and subordinate species in the plant community (Urcelay and Díaz, 2003).

AMF are thought to be especially important to desert ecosystems, because AMF are known to confer drought tolerance (Shi et al., 2015) via increased phosphorus uptake to host plants (Michelsen and Rosendahl, 1990; Shi et al., 2011). However, not all plant species form AM associations, and not all AM plant species show clear nutritional benefits from colonization by mycorrhizal fungi under all growth conditions (Smith and Smith, 2012; Correa et al., 2015). Plant communities may often include species with varying response to the presence of AMF. This variation may range from nonmycorrhizal plants with benign or possibly antagonistic interactions with the fungi (Smith and Smith, 2012), to highly responsive plant species with positive growth responses to AM association (Smith and Read, 2008). The composition of natural plant communities often includes plant species from across this response spectrum, and may be determined by differential contributions of the mycorrhizal fungi to individual plant species fitness. Additionally, the extent of host-plant benefit from mycorrhizas is also density dependent (Facelli $e t$ al., 1999; Shi et al., 2013) and may be influenced by neighbour competition (Radic et al., 2012).

Using a fungicide to suppress the AM associations' development can be an effective approach to study the influence of AM symbiosis. The systemic fungicide benomyl, with its active degradation component carbendazim, is known to reduce AM associations (O'Connor et al., 2002; Dhillion and Gardsjord, 2004; Kula and Hartnett, 2015). Moreover, O'Connor et al. (2002) revealed that benomyl had a minor effect on nontarget soil fungi.

This study is designed to test experimentally the relationship between mycorrhizal responsiveness of plants from a desert herbland and the influence of mycorrhizas on the diversity, density, species richness and productivity in this plant community. To test this relationship, the mycorrhizal responsiveness of plant species from a desert herbland is assessed in a pot experiment and changes of plant community structure in field are measured after formation of mycorrhizas had been suppressed by fungicide application.

\section{Materials and Methods}

\section{Study area}

Gurbantonggut Desert, located in the hinterland of the Junggar Basin, lies at latitude $44^{\circ} 11^{\prime}-46^{\circ} 20^{\prime} \mathrm{N}$ and longitude $84^{\circ} 31^{\prime}-90^{\circ} 00^{\prime}$ E. It covers an area of $48,800 \mathrm{~km}^{2}$ and is the largest fixed and semi-fixed desert in China. The main morphological dune types in the desert are balk-hollow dune ridge and dentritic dune ridge, which are generally a few hundred meters to more than $10 \mathrm{~km}$ in length, $10-50 \mathrm{~m}$ in height and orientate from north to south. The inter-ridge and middle to lower parts of a dune are stabilized but the crests of dune often have $10-40 \mathrm{~m}$ wide mobile zone. Under the action of bi-directional winds, sand materials move leftward and rightward and extend along the crest line of dune (Wang et al., 1998). Annual accumulated temperature varies between 3000 and $3,500{ }^{\circ} \mathrm{C}$ with annual mean temperature of $6-10{ }^{\circ} \mathrm{C}$, annual precipitation is $70-150$ $\mathrm{mm}$ with a mean $\sim 143 \mathrm{~mm}$ and annual evaporation exceeds $2,000 \mathrm{~mm}$. It belongs climatically to the typical inland arid zone. There is a stable accumulated snow with a thickness of $20 \mathrm{~cm}$ in winter. Precipitation is more in spring and summer than in autumn and winter, such water and heat allocation pattern creates a favorable condition for the growth and development of ephemeral plants.

Two experiments were conducted at Gurbantonggut Desert

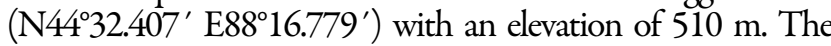
site has been protected to prevent grazing by large herbivores since 2004. The study site is located in the inerridge of dunes. Haloxoylon persicum is a widespread species in the Gurbantunggut Desert and it generally occupies the middle to upper parts of dunes. Interdune depression and middle to lower parts of sand dune are occupied by Ephedra distachya, and understory vegetation is characterized by annual herbs dominated by the ephemeral species Erodium oxyrrhynchum. All plant species belonged to annual herbs except for a short-life perennial Carex physodes. In April, May and June, this kind herbaceous plant mean coverage reached $13.9 \%, 40.2 \%$ and $14.1 \%$, respectively in Guerbantonggut desert (Wang et al., 2003).

Soil properties of the sites were: $\mathrm{pH}\left(\mathrm{H}_{2} \mathrm{O}, 1: 5 \mathrm{soil} /\right.$ water ratio) 7.87 unit, organic matter content (Schollenberger method) $0.18 \%$, available P (Olsen method) $1.65 \mathrm{mg} / \mathrm{kg}$, electrical conductivity $0.71 \mathrm{dS} / \mathrm{m}^{-1}$.

\section{Field experiment design}

In early spring, eighteen $1.5 \mathrm{~m}^{2}$ plots were established in six blocks in open herbland (>10 m to the nearest Haloxoylon persicum or Ephedra distachya). No live plants at the beginning of the growing season. Each plot was separated from the others plots by a 2-m spacing and was divided into a central zone of 1 $\mathrm{m}^{2}$ and a surrounding buffer zone to reduce edge effects from surrounding untreated vegetation. Plots in each block were randomly assigned to one of the three treatments (mycorrhizasuppressed, watered and without watered treatment as control). The dosage of fungicide was designed according to O'Connor $e t$ al. (2002). Mycorrhiza-suppressed plots received the fungicide benomyl as a soil drench ( $9 \mathrm{~g}$ active ingredient (a.i.) in $15 \mathrm{~L}$ of water per plot). Watered plots received $15 \mathrm{~L}$ of water per plot and control plots received no amendments. Treatments began on 25 March and were repeated every 15 days until the end of the experiment (i.e. Majority of plants in plots began to die). It was necessary to include a receiving only water to determine effects of additional water on the vegetation at this arid site. At the same time, a control is designed without water and benomyl.

\section{Mycorrhizal colonization}

Assessment of the effectiveness of benomyl for suppression of AMF was made by collecting roots from field plots on 25 May, 2005. Six plants that density more than $10 \mathrm{~m}^{-2}$ in any one treatment were collected. The collected six species included Alyssum linifolium (Cruciferae), Erodium oxyrrhynchum (Geraniaceae), Carex physodes (Cyperaceae), Hyalea pulchella (Compositae), Ceratocarpus arenarius (Chenopodiaceae), and Trigonella arcuata (Fabaceae). Roots from each species in each 
plot were cut into approximately $1.0 \mathrm{~cm}$ - long segments and cleared and stained with $0.5 \%(\mathrm{w} / \mathrm{v})$ acid fuchsin (Biermann and Linderman, 1981). Thirty root fragments (approximately $1 \mathrm{~cm}$ long) were mounted on slides in a polyvinyl alcohol-lactic acidglycerol solution (Koske and Tessier, 1983) and examined at 100-400× magnification under an Olympus BX50 microscope with an automatic photo- micrographic system for the presence of AM fungal structures. The percentage of root length colonized by AM fungal structures was determined using the magnified line-intersect method of McGonigle et al. (1990). The hyphae, arbuscules, and vesicles were recorded when any of them were presented at an intersection.

\section{Plantproductivity and diversity}

On 25 May, 2 months after treatments began (i.e. after 4 applications), all plants were dug out from each plots. Each Plant was separated into both shoot and root. Roots were used to measure mycorrhizal colonization. The shoots were dried overnight at $80^{\circ} \mathrm{C}$ in an oven before assessment of aboveground dry weights. Plant number per species was also used to calculate plant density, species richness (mean number of species per plot) and diversity (Shannon $H^{\prime}$ ).

\section{Mycorrbizal responsiveness}

Mycorrhizal responsiveness of the major plants in field plots was assessed in two different ways. At the initial stages of the experiment (31 March), polyvinylchloride (PVC) cylinders 15 $\mathrm{cm}$ tall and $10 \mathrm{~cm}$ in diameter were driven into the soil in an area adjacent to the experimental plot. The cylinders were positioned in such a way that 24 cores were collected for the major plant species Erodium oxyrrhynchum; cores had a PVC cap on the bottom, which had holes drilled in to allow free drainage. Seedlings were all at the cotyledon or first-leaf stage of growth at this early stage of the season. Cores were removed to a glasshouse and kept weeded and watered for 2 months. At the end of the first and third weeks in the glasshouse, half the cores were lowered into a solution of $1.5 \mathrm{gl}^{-1}$ benomyl (a.i) for $5 \mathrm{~min}$.

These cores were designated as the mycorrhiza-suppressed treatment. The remaining cores were lowered into water for an equal length of time and were designated as the mycorrhizal treatment. Plants were harvested after 2 months' growth (stage of fruit) and the mycorrhizal colonization was assessed using the methods described above.

\section{Nutrient analysis}

$\mathrm{N}, \mathrm{P}$ and $\mathrm{K}$ concentrations in shoot of five common host plants were measured in different treatments in field plots. Dried shoot tissues were digested with concentrated $\mathrm{HClO}_{4}, \mathrm{H}_{2} \mathrm{SO}_{4}$ and $\mathrm{HF}$, and $\mathrm{N}, \mathrm{P}$ and $\mathrm{K}$ were determinted by the Kjeldahl method, the molybdo-vanado- phosphate method, and flame photometric analysis method.

\section{Statistical analysis}

All data were subjected to one-way ANOVA using SPSS software version 11.0. Treatments were separated by Leastsignificant different (LSD) test for significantly different means in all experiments.

\section{Results}

In the responsiveness of dominant plant $E$. oxyrrhynchum test with field cores, root colonization was significantly reduced when cores were treated with benomyl (Table 1). Growth of the dominant was significant decreased by reduction in root colonization in benomyl-treated cores. The dry matter of shoot and root and the fruit number were significantly reduced when benomyl was applied. Their mycorrhizal response was 190, 75 and 122, respectively (Table 1). However, the ratio of root to shoot was increased in benomyl-treated cores.

The application of benomyl as a soil drench in field plots successful suppressed mycorrhizal colonization with respect to controls throughout the period. In harvest, mycorrhizal colonization of six plants (A. linifolium, E. oxyrrbynchum, $C$. physodes, $H$. pulchella, C. arenarius, $T$. arcuata) that plant density more than 10 in $^{-2}$ in any one treatment among three treatments were measured (Fig. 1). Mycorrhizal colonization of the dominant species E. oxyrrhynchum was significant reduced in benomyl-treated plots ( $8.58 \%$ ) comparing to these treated with water $(36.17 \%)$. The mycorrhizal colonization of $\mathrm{H}$. pulchella was significantly decreased in benomyl-treated plots. However, there were nodifference between control and watertreated plots. The same colonization trend was observed in the roots of $C$. arenarius and T. arcuata. Mycorrhizal colonization in water-treated plots was higher than in control and benomyltreated plots. The mycorrhizal colonization of $C$. physodes was not significant difference among three treatments. Among three treatments, no colonization was found in the roots of $A$. linifolium (Fig. 1). The spore density was also significantly reduced when benomyl was applied in filed plots (Table 2).

The total aboveground dry matter production was determined among three treatments in filed plots (Table 2). The reduction of total aboveground dry matter production was significant relative to water-treated plots when AMF were suppressed with benomyl. However, no significant difference was observed between control and benomyl-treated plots.

The growth response of six common plant species was calculated. The shoot biomass in control plots was low except for $C$. physodes relative to other two treatments though the response was varied with the difference of plant species, while the difference among three treatments was not significant (Fig. 2). The shoot dry biomass of $A$. linifolium and $C$. arenarius increased when benomyl was applied in plots comparing to water-treated plots (Fig. 2). The aboveground dry biomass of other four species was higher in water treatment than in benomyl-treated plots (Fig. 2). Among six common plant species, the response of $C$. physodes was most with the increment of $211 \%$ and $280 \%$ relative to controls and benomyl-treated plots, respectively (Fig. 2).

Table 1. Growth response of Erodium oxyrrhynchum to mycorrhizal colonization in intact cores. Each value was expressed by the mean \pm SE

\begin{tabular}{ccccc}
\hline Treatments & $\begin{array}{c}\text { Shoot dry matter } \\
\left(\mathrm{g} \mathrm{plant}^{-1}\right)\end{array}$ & $\begin{array}{c}\text { Root dry matter } \\
\left(\mathrm{g} \mathrm{plant}^{-1}\right)\end{array}$ & $\begin{array}{c}\text { Fruit } \\
(\text { No. plant }\end{array}$ & $\begin{array}{c}\text { Root length colonized } \\
(\%)\end{array}$ \\
\hline Control & $2.03 \pm 0.30 \mathrm{a}^{1}$ & $0.28 \pm 0.03 \mathrm{a}$ & $4.29 \pm 0.46 \mathrm{a}$ & $45.6 \pm 6.7 \mathrm{a}$ \\
Fungicide & $0.70 \pm 0.07 \mathrm{~b}$ & $0.16 \pm 0.02 \mathrm{~b}$ & $1.93 \pm 0.26 \mathrm{~b}$ & $0.7 \pm 0.7 \mathrm{~b}$ \\
$\mathrm{MR}^{2}$ & 190 & 75 & 122 & 2813 \\
\hline
\end{tabular}


Table 2. Response of total above-ground dry matter production, soil water content and AM fungal spore density in different treatment in field plots. Each value was expressed by the mean \pm SE

\begin{tabular}{cccc}
\hline Treatments & Total aboveground dry matter production $\left(\mathrm{g} \mathrm{m}^{-2}\right)$ & Soil water content $(\%)$ & AM fungal spore density $\left(\right.$ Number $30 \mathrm{~g}^{2}$ soil $\left.{ }^{-1}\right)$ \\
\hline Control & $19.9 \pm 2.3 \mathrm{~b}^{*}$ & $0.62 \pm 0.04 \mathrm{~b}$ & $8.0 \pm 1.9 \mathrm{a}$ \\
Fungicide & $26.9 \pm 4.7 \mathrm{~b}$ & $1.05 \pm 0.07 \mathrm{a}$ & $4.2 \pm 0.4 \mathrm{~b}$ \\
Water & $44.5 \pm 4.1 \mathrm{a}$ & $0.90 \pm 0.08 \mathrm{a}$ & $8.2 \pm 0.6 \mathrm{a}$ \\
\hline${ }^{*}$ Different letters indicate significant difference $(\mathrm{p}<0.05)$ between treatments & &
\end{tabular}

${ }^{*}$ Different letters indicate significant difference $(\mathrm{p}<0.05)$ between treatments

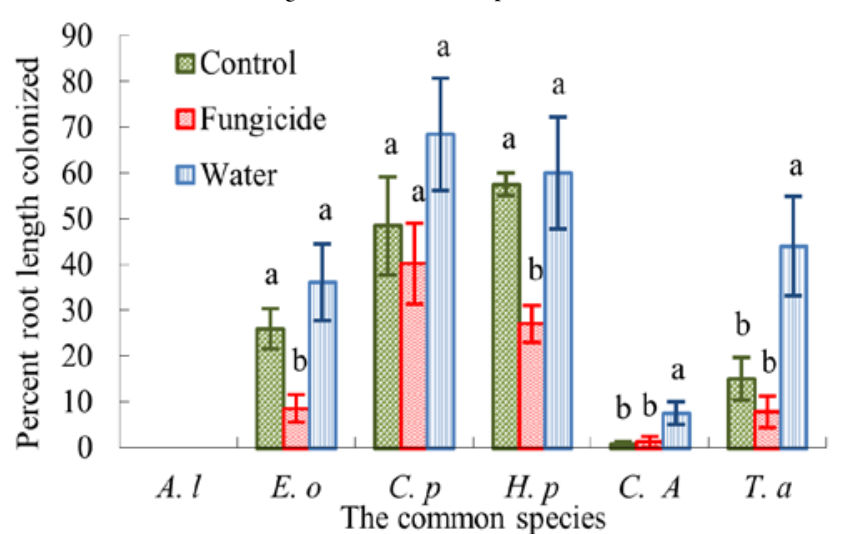

Fig. 1. Response of mycorrhizal colonization of the common plant species (the plant density $>10 \mathrm{~m}^{-2}$ in any one treatment) in different treatments in field plots. A. 1 - A. linifolium; E.o E. oxyrrhynchum; C.p - C. physodes; H.p - H. pulchella; C.a - C. arenarius; T.a - T. arcuata. Error bars represent \pm SE. Different letters indicate significant difference $(p<0.05)$ between treatment

In field plots, plant density, plant species richness and diversity were recorded throughout one growing season (Fig. 3). Plant density and species diversity were the highest in 25 April about 4 weeks after germination (Fig. 3a, b). The plant density was significantly reduced in field plots by application of benomyl relative to water-treated and control plots in harvest. However, the difference between water-treated plots and other two treatments began to present in 9 May (i.e. about 6 weeks after germination) (Fig. 3a). Plant species diversity and richness showed significant different in harvest (Fig. 3b, c). The plant species richness and diversity in water-treated plots were significant higher than these in benomyl-treated plots (Fig. 3b, c).

The density of six common species (plant density more than $10 \mathrm{~m}^{-2}$ ) was also different with the change of treatments and growing stages (Fig. 4). The density of the dominant species $E$. oxyrrhynchum was up to the highest in 25 April about 4 weeks after germination. The significant difference was observed from 9 May. The density was significantly reduced by application of benomyl comparing to the plots treated with water though the difference in the two treatments was not significant with control (Fig. 4). The non-mycorrhizal plant $A$. linifolium was not present. The most density presented in 25 April. The differences were twice observed in 25 April and 25 May, respectively (Fig. 4). No significant difference was observed in plant density of $C$. physodes and $C$. arenarius among three treatments during growing season (Fig. 4).The density of $T$. arcuata exhibited different trend with the variation of growing stages. The density of the benomyl-treated plots was significant higher than that of control in 9 May. And there were not significant different between water-treated plots and the rest two treatments. However, the water-treated plot

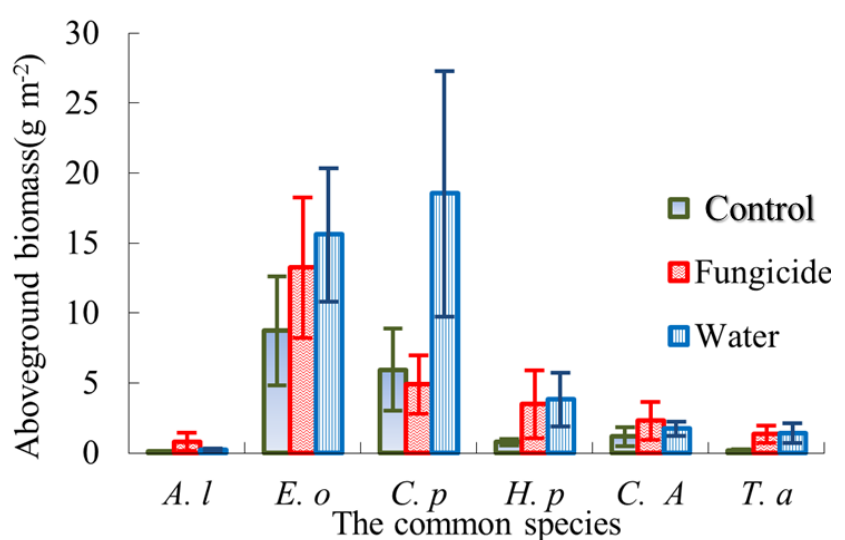

Fig. 2. Response of aboveground dry matter production of the common plant species (the common plant density $>10 \mathrm{~m}^{-2}$ in any one treatment) in different treatments in field plots. A. 1 A. linifolium; E.o - E. oxyrrhynchum; C.p - C. physodes; H.p H. pulchella; C.a - C. arenarius; T.a - T. arcuata. Error bars represent \pm SE

was significant higher than the rest two treatments in harvest (Fig. 4). The density of $H$. pulchella always increased in growing season. Its density presented significant differences in harvest (Fig. 4).

$\mathrm{N}, \mathrm{P}$ and $\mathrm{K}$ concentrations in shoot of five common mycorrhizal host plants were measured in different treatments in field plots (Table 3). $\mathrm{P}$ and $\mathrm{K}$ concentrations of $C$. physodes in benomyl-treated plots were significant higher than those in controls and water treatments. $\mathrm{N}$ and $\mathrm{P}$ concentrations of $T$. arcuata presented the same trend, which water and benomyl treatments were significant higher than those in controls. No significant differences were observed in the $\mathrm{N}, \mathrm{P}$ and $\mathrm{K}$ concentrations of the rest plant species except for $C$. physodes and $T$. arcuata in different treated plots.

\section{Discussion}

In natural ecosystems, plant communities are associated with communities of AMF (Helgason et al., 1998; Shi et al., 2013, 2014). We report community composition was significant altered by suppression of mycorrhizal activity in this desert herbland. Plant species diversity and richness both decreased when mycorrhizal colonization was suppressed in desert herbland. This result is contrary to the result reported by O'Connor et al. (2002) in a semiarid herbland who shows that the suppression of AMF increase plant species diversity and has no effect on plant species richness, which supports the findings of Gange et al. (1990) and Heijden et al. (1998) that AM fungi increases plant species diversity. The difference of plant density is observed until late stage in field plots. It is possible that it might take time before benomyl application affects the plant density. This finding is similar to the influence of benomyl on AMF inoculum potential that made by Dhillion and 


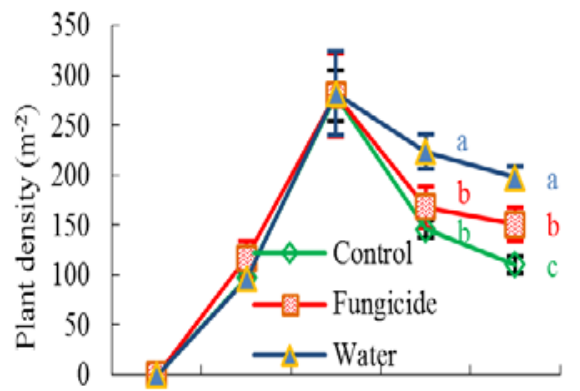

Mar.-25 Apr.-9 Apr.-25 May-9 May-25

Date

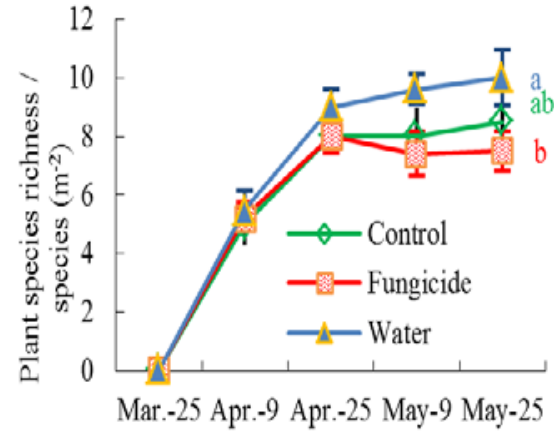

Date

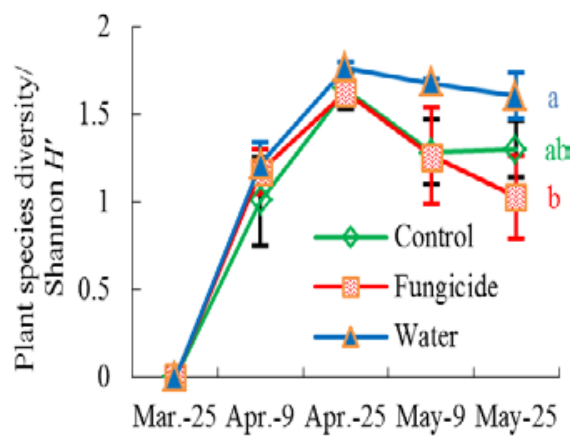

Date

Fig. 3. The changes of a) coverage, b) density, c) species richness, d) diversity, and e) species evenness in different treatments in field plots. Error bars represent \pm SE. Different letters indicate significant difference $(p<0.05)$ between treatments

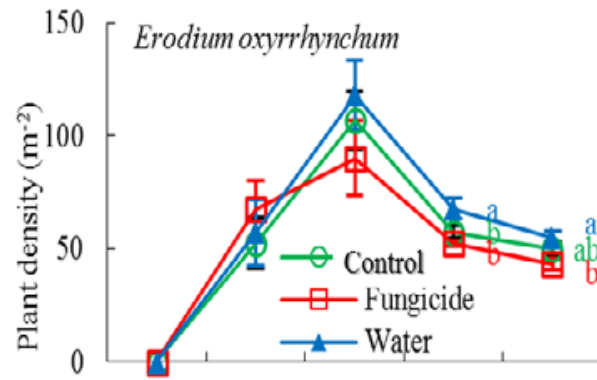

Mar.-25 Apr.-9 Apr.-25 May-9 May-25

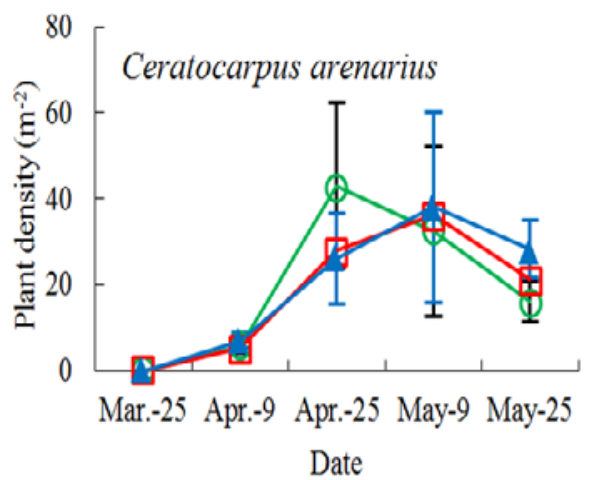

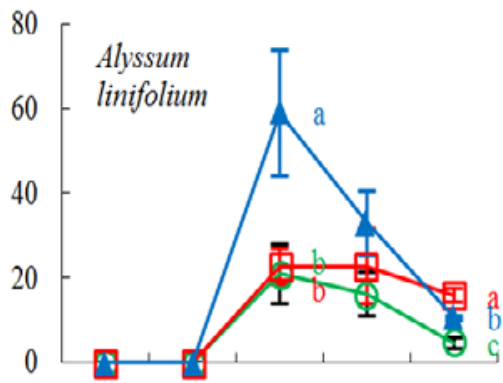

Mar.-25 Apr.-9 Apr.-25 May-9 May-25

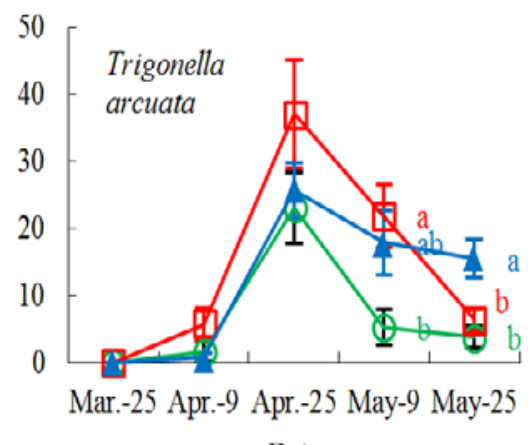

Date
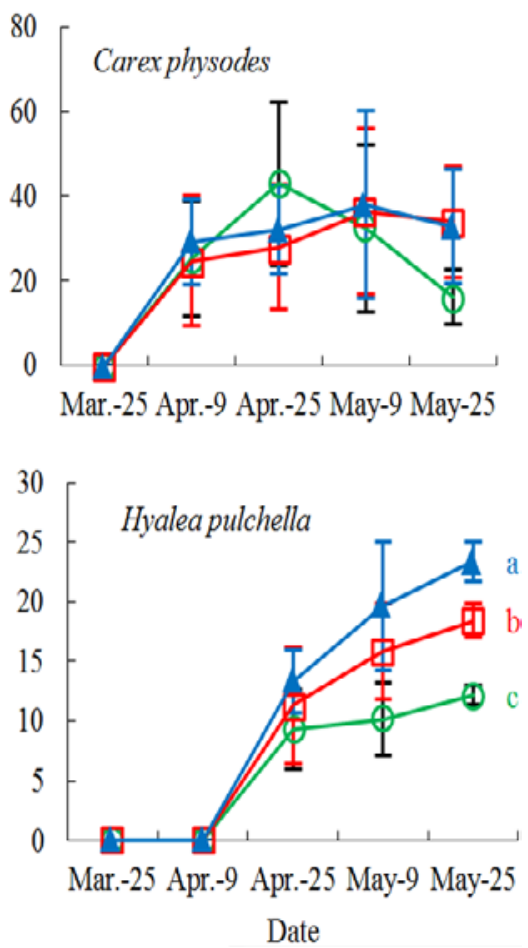

Fig. 4. Response of plant community of the common plant species (the plant density $>10 \mathrm{~m}^{-2}$ in any one treatment) in different treatments in field plots. Error bars represent \pm SE. Different letters indicate significant difference $(\mathrm{p}<0.05)$ between treatments

Table 3. N, P and K concentrations in shoot of five common host plants in different treatments in field plots

\begin{tabular}{ccccc}
\hline Host plants & Treatments & $\mathrm{N}(\%)$ & $\mathrm{P}(\%)$ & $\mathrm{K}(\%)$ \\
\hline E. oxyrrhynchum & $\mathrm{CK}$ & $1.183 \pm 0.102 \mathrm{a}^{*}$ & $0.236 \pm 0.029 \mathrm{a}$ & $1.184 \pm 0.063 \mathrm{a}$ \\
& Fungicide & $0.970 \pm 0.121 \mathrm{a}$ & $0.231 \pm 0.014 \mathrm{a}$ & $1.146 \pm 0.056 \mathrm{a}$ \\
& Water & $1.018 \pm 0.127 \mathrm{a}$ & $0.231 \pm 0.010 \mathrm{a}$ & $1.265 \pm 0.046 \mathrm{a}$ \\
\hline C.physodes & $\mathrm{CK}$ & $0.658 \pm 0.084 \mathrm{a}$ & $0.063 \pm 0.006 \mathrm{~b}$ & $0.477 \pm 0.052 \mathrm{~b}$ \\
& Fungicide & $0.713 \pm 0.057 \mathrm{a}$ & $0.099 \pm 0.009 \mathrm{a}$ & $0.712 \pm 0.056 \mathrm{a}$ \\
\hline C. arenarius & Water & $0.673 \pm 0.049 \mathrm{a}$ & $0.072 \pm 0.003 \mathrm{~b}$ & $0.555 \pm 0.024 \mathrm{~b}$ \\
\hline & $\mathrm{CK}$ & $1.245 \pm 0.177 \mathrm{a}$ & $0.178 \pm 0.013 \mathrm{a}$ & $1.668 \pm 0.105 \mathrm{a}$ \\
\hline T. arcuata & Fungicide & $1.320 \pm 0.180 \mathrm{a}$ & $0.191 \pm 0.008 \mathrm{a}$ & $1.844 \pm 0.092 \mathrm{a}$ \\
& Water & $1.186 \pm 0.121 \mathrm{a}$ & $0.190 \pm 0.012 \mathrm{a}$ & $1.759 \pm 0.112 \mathrm{a}$ \\
\hline H. pulchella & CK & $1.136 \pm 0.090 \mathrm{~b}$ & $0.152 \pm 0.011 \mathrm{~b}$ & $1.191 \pm 0.072 \mathrm{~b}$ \\
& Fungicide & $1.955 \pm 0.094 \mathrm{a}$ & $0.267 \pm 0.014 \mathrm{a}$ & $1.343 \pm 0.089 \mathrm{ab}$ \\
\hline & Water & $1.794 \pm 0.091 \mathrm{a}$ & $0.280 \pm 0.006 \mathrm{a}$ & $1.461 \pm 0.068 \mathrm{a}$ \\
\hline & CK & $1.178 \pm 0.231 \mathrm{a}$ & $0.190 \pm 0.018 \mathrm{a}$ & $1.482 \pm 0.051 \mathrm{a}$ \\
& Fungicide & $1.182 \pm 0.129 \mathrm{a}$ & $0.209 \pm 0.019 \mathrm{a}$ & $1.668 \pm 0.063 \mathrm{a}$ \\
\hline
\end{tabular}

${ }^{*}$ Different letters indicate significant difference $(\mathrm{p}<0.05)$ between treatments in the each host plant 
306

Gardsjord (2004). This may explain why the effect of benomyl on plant species diversity and richness appeared in late of growing season. In the six common species, plant density of mycorrhizal plant E. oxyrrhynchum, $H$. pulchella and $T$. arcuata is significantly reduced by suppressing AMF. It is highly probable that arbuscular mycorrhizas increased the absorption of water and mineral nutrients. As a possible result, the lifecycle of host plants is prolonged because the symbiosis has a positive effect regarding plant water potential especially for plants under drought stress (Augé, 2001). However, the suppression of AMF increases the density of nonmycorrhizal host $A$. linifolium. This supports the results of Smith and Smith (2012). The total plant density and a few common species in benoyml treated plots are higher than in controls. This may be partly induced by improving soil water content because the soil water content is significant low in control plots. Research has shown that water is the most common abiotic factors that limit plant growth in arid environments (Cui et al., 2015).

The employment of benomyl significantly decreases the mycorrhizal colonization in soil cores and all mycorrhizal plants except for $C$. physodes. This finding is consistent with a lot of previous researches who conclude that AM symbiosis is able to be effectively suppressed by benomyl (O'Connor et al., 2002; Dhillion and Gardsjord, 2004; Kula and Hartnett, 2015). The spore density is also reduced by application of benomyl. Our results conflict with the experiment in boreal grasslands of Dhillion and Gardsjord (2004). The possible reason was that the dose in the experiment $(0.12 \mathrm{~g}$ active ingredient in $1 \mathrm{~L}$ of water per $1 \mathrm{~m}^{2}$ plot each times) of Dhillion and Gardsjord (2004) was smaller than in our experiments with the dose of $9 \mathrm{~g}$ active ingredient in $15 \mathrm{~L}$ of water per 1.5 $\mathrm{m}^{2}$ plot each times because Schweiger and Jakobsen (1998) shows that AMF presented different response to the different dosage of fungicide.

Negative growth response to interaction with $\mathrm{AM}$ fungi has been previous observed for non-mycorrhizal plants (O'Connor et al., 2002; Smith and Smith, 2012). The shoot dry biomass of non-mycorrhizal plant $A$. linifolium increases when AM fungi are suppressed though no different is observed. Furthermore, many studies document detrimental growth effects due to mycorrhizal fungi (Michelsen and Rosendahl, 1990; Smith and Smith, 2012). In our results, the negative effect of AMF was found in $C$. arenarius though the effect was not significant. No positive effects were also significant despite the shoot dry biomass was higher in water treatment than in benomyl-treated plots.

The total aboveground biomass was significant reduced by treated with benomyl relative water-treated plots. This possible is partly explained that AMF could improve plant growth. This presumption was confirmed by the data of shoot biomass in our experiment of soil cores. The mycorrhizal response of the shoot dry matter was up to 190 in our experiment of soil cores. In addition, the root dry matter was also significantly increased in control cores. The growth response was similar to the response of Atriplex nummularia to AMF Glomus intraradices (Plenchettea and Duponnoisb, 2005). Probably, the increase of plant density in water-treated plots was partly contribution to the increment of total aboveground dry matter production. It may be caused by the difference of soil water that no significant difference was found between benomyl-treated plots and controls because water is the most common abiotic factors that limit plant growth in arid environments (Cui et al., 2015).

Restoration of species-rich communities is an important way to counteract global losses in biodiversity (Young, 2000). Numerous reports deal with ecological restoration through the establishment of planted vegetation and indicate that biodiversity restoration is an important condition for regional ecological health (Odum, 1989; Aronson et al., 2016). Biodiversity is not only closely related to biomass production (Tilman et al., 1996; Bullock et al., 2001; Cardinale et al., 2013), but is also related to ecosystem stability (Tilman, 1999; Eisenhauer et al., 2016). As expected, AMF can improve the plant density, species richness and diversity and plant productivity in desert herbland. The inspiring results give us confidence to rehabilitate desert ecosystem by utilizing AMF. However, the effect of AMF still need to be further experimented.

\section{Conclusions}

The results of the present study indicate that AM may play an important role in the development and maintenance of desert ephemeral communities. AM fungi are very important in desert ecosystem for the increment maintaining of plant biodiversity, richness and productivity.

\section{Acknowledgements}

The project was supported by Key Laboratory of Mountain Surface Processes and Ecological Regulation, Chinese Academy of Sciences (No. 20160618), National Natural Science Foundation of China (31670499), and Funds for Innovation Research Team in Henan University of Science and Technology (2015TTD002), the Plan for Scientific Innovation Talent of Henan Province (154100510010).

\section{References}

Aronson JC, Blatt CM, Aronson, TB (2016). Restoring ecosystem health to improve human health and well-being: physicians and restoration ecologists unite in a common cause. Ecology and Society 21(4):39.

Augé RM (2001). Water relations, drought and VA mycorrhizal symbiosis. Mycorrhiza 11:3-42.

Bergelson JM, Crawley JM (1988). Mycorrhizal infection and plant species diversity. Nature 334:202.

Biermann B, Linderman RG (1981). Quantifying vesicular-arbuscular mycorrhizae: A proposed method towards standardization. New Phytologist 87:63-67.

Bullock JM, Pywell RF, Burke MJW, Walker KJ (2001). Restoration of biodiversity enhances agricultural production. Ecology Letters 4:185189.

Cardinale BJ, Gross K, Fritschie K, Flombaum P, Fox JW, Rixen C, ... Wilsey BJ (2013). Biodiversity simultaneously enhances the production and stability of community biomass, but the effects are independent. Ecology 94(8):1697-1707.

Correa A, Cruz C, Ferrol N (2015). Nitrogen and carbon/nitrogen dynamics in arbuscular mycorrhiza: the great unknown. Mycorrhiza 25(7):499-515.

Cui YQ, MaJY,Sun W,Sun,JH,Duan,ZH(2015). A preliminary study of water use strategy of desert plants in Dunhuang, China. Journal of Arid Land7(1):73-81. 
Dhillion SS, Gardsjord TL (2004). Arbuscular mycorrhizas influence plant diversity, productivity, and nutrients in boreal grasslands. Canadian Journal of Botany 82:104114.

Eisenhauer N, Barnes AD, Cesarz S, Craven D, Ferlian O, Gottschall F, ... Thakur MP (2016). Biodiversity-ecosystem function experiments reveal the mechanisms underlying the consequences of biodiversity change in real world ecosystems. Journal of Vegetation Science 27(5):1061-1070.

Facelli E, Facelli JM, Smith SE, Mclaughlin MJ (1999). Interactive effects of arbuscular mycorrhizal symbiosis, intraspecific competition and resource availability on Trifolium subterraneum cv. Mt. Barker. New Phytologist 141:535-547.

Fessel C, Meier IC, Leuschner C (2016). Relationship between species diversity, biomass and light transmittance in temperate semi-natural grasslands: is productivity enhanced by complementary light capture? Journal of Vegetation Science 27(1):144-155.

Gange AC, Brown VK, Farmer LM (1990). A test of mycorrhizal benefit in an early successional plant community. New Phytologist 115:85-91.

Givnish TJ (1994). Does diversity beget stability? Nature 371:113-114.

Heijden van der MGA, Klironomos JN, Ursic M, Moutogis P, StreitwolfEngel R, Boller T, ... Sanders IR (1998). Mycorrhizal fungal diversity determines plant biodiversity, ecosystem variability and productivity. Nature 396:69-72.

Helgason T, Daniell TJ, Husband R, Fitter AH, Young JP (1998). Ploughingup the wood-wide web? Nature 394:431.

Horn S, Hempel S, Verbruggen E, RilligMC, Caruso T (2017). Linking the community structure of arbuscular mycorrhizal fungi and plants: a story of interdependence? The ISMEJournal 11(6):1400-1411.

Huston MA (1997). Hidden treatments in ecological experiments: reevaluating the ecosystem function of biodiversity. Oecologia 110:449 460.

Jing X, Sanders NJ, Shi Y, Chu H, Classen AT, Zhao K, ... He JS (2015). The links between ecosystem multifunctionality and above- and belowground biodiversity are mediated by climate. Nature Communications 6:8159.

Klironomos JN, McCune J, Hart M, Neville J (2000). The influence of arbuscular mycorrhizae on the relationship between plant diversity and productivity. EcologyLetters 3(2):137-141.

Koske RE, Tessier B (1983). A convenient, permanent slide mounting medium. Newsletter of the Mycological Society of America 34:59.

Kula AAR, Hartnett DC (2015). Effects of mycorrhizal symbiosis on aboveground arthropod herbivory in tallgrass prairie: an in situ experiment. PlantEcology 216(4):589-597.

Lin G, McCormack ML, Guo D (2015). Arbuscular mycorrhizal fungal effects on plant competition and community structure. Journal of Ecology 103:12241232.

McGonigle TP, Miller MH, Evans DG, Fairchild GL, Swan JA (1990) A new method which gives an objective measure of colonization of roots by vesicular arbuscular mycorrhizal fungi. New Phytologist 115:495501.

Michelsen A, Rosendahl S (1990). The effect of VA mycorrhizal fungi, phosphorus and drought stress on the growth of Acacia nilotica and Leucaenaleucocephala seedlings. Plant and Soil 124:7-13.

O'Connor PJ, Smith SE, Smith FA (2002). Arbuscular mycorrhizas influence plant diversity and community structure in semiarid hetbly New Phytologist 154:209-218.

Odum EP (1989). Ecology and our endangered life-support systems. Sinauer Associates, Sunderland, Massachusetts.

Plenchettea C, Duponnoisb R (2005). Growth response of the saltbush Atriplex nummularia $\mathrm{L}$. to inoculation with the arbuscular mycorrhizal fungus Glomus intraradices. Journal of Arid Environment 61:535-540.

Radic T, Hancevic K, Likar M, Protega I, Jug-Dujakovic M, Bogdanovic I (2012). Neighbouring weeds influence the formation of arbuscular mycorrhizain grapevine. Symbiosis 56(3):111-120.

Schweiger PF, Jakobsen I (1998). Dose-response relationships between four pesticides and phosphorus uptake by hyphae of arbuscular mycorrhizas. Soil Biology and Biochemistry 30:1415-1422.

Shi ZY, Liu DH, Wang FY (2013). Spatial variation of arbuscular mycorrhizal fungi in two vegetation types in Gurbantonggut Desert. Contemporary Problems of Ecology 6:455-464.

ShiZY, Mickan B, Feng G, Chen YL (2015). Arbuscular mycorrhizal fungi improved plant growth and nutrient acquisition of desert ephemeral Plantago minuta under variable soil water conditions. Journal of Arid Land 7:414-420.

Shi ZY, Wang FY, Zhang C, Yang Z (2011). Exploitation of phosphorus patches with different phosphorus enrichment by three arbuscular mycorrhizal fungi.Journal of Plant Nutrition 34:1096-1106.

Shi ZY, Wang FY, Zhang K, Chen Y (2014). Diversity and distribution of arbuscular mycorrhizal fungi along altitudinal gradients in Mount Taibai of the Qinling Mountains. Canadian Journal of Microbiology 60:811-818.

Smith SE, ReadDJ (2008). Mycorrhizal symbiosis, 3nd edn. Academic Press, London.

Smith SE, Smith FA (2012). Fresh perspectives on the roles of arbuscular mycorrhizal fungi in plant nutrition and growth. Mycologia 104(1):113.

Tilman D (1999). The ecological consequences of changes in biodiversity: a search for general principles. Ecology 80:1455-1474.

Tilman D, Knops J, Wedin D, Reich P, Ritchie M, Siemann E (1997). The influence of functional diversity and composition on ecosystem processes. Science 277:1300-1302.

Tilman D, Wedin D, Knops J (1996). Productivity and sustainability influenced by biodiversity in grassland systems. Nature 379:718-720.

Urcelay C, Díaz S (2003). The mycorrhizal dependence of subordinates determines the effect of arbuscular mycorrhizal fungi on plant diversity. Ecology Letters 6:388-391.

Wang XQ, Jiang J, Lei JQ, Zhang W, Qian Y (2003). The distribution of ephemeral vegetation on the longitudinal dune surface and its stabilization significance in the Gurbantunggut Desert. Acta GeographicaSinica 58:598-605.

Wang XQ, Lei JQ (1998). The characteristics of erosion and deposition on the longitudinal dune surface in Gurbantunggut Desert. Arid Zone Research 15(1):35-39.

Wilsey BJ, Potvin C (2000). Biodiversity and ecosystem functioning: importance of species evenness in an old field. Ecology 81:887-892.

Young TP (2000). Restoration ecology and conservation biology. Biological Conservation 92:73-83. 